\title{
Effects of Empowering Families on Improving Quality of Life for Children with Chronic Kidney Diseases
}

\author{
Amal Abdelrazik Fathalla Ahamed \\ Department of Pediatric Nursing, Faculty of Nursing, Menoufia University, Shebin El-Kom, Egypt
}

Email address:

Hassan4337@gmail.com

\section{To cite this article:}

Amal Abdelrazik Fathalla. Effects of Empowering Families on Improving Quality of Life for Children with Chronic Kidney Diseases. American Journal of Nursing Science. Vol. 7, No. 1, 2018, pp. 14-22. doi: 10.11648/j.ajns.20180701.12

Received: November 18, 2017; Accepted: December 4, 2017; Published: January 16, 2018

\begin{abstract}
Background: One of the most chronic diseases can effect on quality of life for children and their families are chronic kidney diseases. It can cause direct adverse impact on children life. So, empowerment of family and children is essential to enhance and improve their quality of life. For this reason, the aim of this study was to evaluate the effect of the family empowerment model on the quality of life for children with chronic kidney diseases. It was hypothesized that children with chronic kidney diseases who received family empowerment model sessions will have better quality of life than children who did not. The design of this study was quasi experimental design. It was conducted in Menoufia University Hospital and Teaching Hospital in Shebin El-Kom in Menoufia governorate. For data collection, a purposive sample of 60 children with chronic kidney diseases and their parents was obtained from the previous mentioned settings. Tools of this study were Social characteristics sheet and the questionnaire of Core Ped QoL, version 4. The results of this study showed that significant improvement in quality of life after implementation of family empowerment model for children with chronic kidney diseases and their parents. It was concluded that that family empowerment model was effective in improved the quality of life for children with chronic kidney diseases. Therefore, this study recommended that this model to be used in inpatient and outpatient children's health care.
\end{abstract}

Keywords: Chronic Kidney Disease, Family Empowerment, Quality of Life

\section{Introduction}

Chronic kidney disease (CKD) and renal failure (RF) is considering major health problems for children less than 18 years. It is gradual loss of renal function that gradually which ultimately leads to end-stage renal disease (ESRD) [1]. Worldwide, there is increase in the number of patients with chronic kidney failure and consequent end stage renal failure. The annual rate of children who develop kidney failure was 1 or 2 new cases in every 100.000 children. In the USA, each year three to five children per million develop CRF [2].

In Egypt, CRF in hospitalized children between births to 15 years of age has been reported to be approximately $1.36 \%$ of all hospitalized patients [3]. Moreover, morbidity and mortality is highly worldwide more than 67,000 deaths occur each year as a result of kidney failure. It incidence is still increase due to poor and low socio-economic standard. Complications related to chronic kidney disease not develop to end stage renal diseases only. It can increase risk for heart disease, failure of growth and development and alteration of lifestyle for children and their parents [4].

Many studies support that early detection and treatment of chronic kidney disease-related complications are very important that help the patient to have better growth and development and better quality of life [5]. Based on the World Health Organization (WHO) statement, "quality of life (QOL) includes individuals' perceptions from their life situation with regard to their culture, value system, goals, expectations, standards, and concerns [6]. Therefore, one of the most important aspects in management of a chronic kidney disease is promotion of patients' QOL, in addition to control of disease signs.

Chronic kidney diseases had negative impact on children life style and this indicates that children and their family need for more support to achieve adjustment [7]. Family has many crisis related to diagnosis of the disease and adjusting it. 
Many families react different responses. Most of the families can successfully adopt themselves with chronic disease of their children. In contrast, some of them also may not be successful in adapt with it [8]. The main causes for that is the family has lack of access to accurate information about the disease, lack of enough support resources, high treatment costs, mental status and social damages [9].

On the other hand, family plays the main role in confirming health and well-being of the children and can have a significant impact on their quality of life. That is why nowadays the health care system continuous act to change care from child-centered care to family-centered one [10]. So, family should receive accurate information about diseases and participate in all the decision-makings related treatment and health care measures for their children [11].

So, one of the most important ways to change and improve QOL in children with chronic kidney diseases is support and empower of their families. Family empowerment includes the interaction of health team with the families, so that it causes change families' life and leads to accomplishment to positive changes in the direction of power, ability, and enhancement of skills in families [12]. From this power children who with chronic kidney diseases have chance to diminish hospitalization costs and number, improve quality of their life (physical and psychosocial), and decrease signs and complications of disease and school absenteeism [13].

Children and their parents are often receiving incomplete, inaccurate and disorganized knowledge given to them by the physicians and nurses at the time of discharge. It is often forgotten which due to lack of ensuring and repetition of knowledge and use of medical terms in this education after discharge. These families should live their life in peace and have good quality of life from the time their children' chronic disease is diagnosed. Also, they have the ability of decisionmaking and determination of priorities for their own needs as well as their children's [14]. The parents' skills should be confirmed by nurses. However, nurses are playing a valuable role in promoting care for children and their families. Therefore, nurses should be provide children and their families with the clinical, educational and administrative supports required which enabling them to adjustment [15]. Therefore, this study aims to evaluate the effect of family empowerment model on QOL of the children with chronic renal diseases, in order to suggest appropriate approaches for improve of their QOL.

\section{Aims of the Study}

This study aimed to evaluate the effect of the family empowerment model on the quality of life in children with chronic kidney diseases.

\section{Hypothesis}

It was hypothesized that children with chronic kidney diseases who received family empowerment model sessions will have better quality of life than children who did not.

\section{Operational Definition}

1. Chronic Kidney diseases: is a slow or gradually progressive loss of kidney function over a period of several years [16]. Eventually the patient has permanent kidney failure

2. Quality of life is the degree of satisfaction with present life circumstances as perceived by the individual. It influenced by present as well as future experiences [17].

3. Family empowerment: is an interactive intervention that nurses use to help patients families and it is designed to aid families through the empowerment process, which consists of phases that correspond to the amount of trust and decision making a family shares with health professionals [18].

\section{Subjects and Method}

This section describes research design, settings, sampling technique, data collection instruments, pilot study, data collection procedures, and data analysis.

\subsection{Research Design}

A quasi-experimental design was utilized.

\subsection{Setting}

This study was conducted at the outpatient clinic of Pediatrics sub-specialists of children's renal diseases in Menoufia University Hospital and Shebin El-Kom Teaching Hospital. In Menoufia University Hospital, the Outpatient clinic was present in the first floor. It included one room for pediatric patients. In Shebin El-Kom Teaching Hospital, the Outpatient clinic was present in the ground floor. It included one room for pediatric patients.

\subsection{Subjects: (Population and Sample)}

A sample of 60 children was included. A simple random sampling technique was used to assign them into study group I and study group II. Sample size has been calculated using the following equation: $n=\left(z^{2} \times p \times q\right) / D^{2}$ at $C I 95 \%$ and power $80 \%$. The sample size was 60 children. Study group I received family empowerment model sessions and study group II did not received sessions. Number of children who were selected from Menoufia University Hospital was 30 children (15 children received family empowerment model sessions and 15 children no received sessions. Number of children who were selected from Teaching Hospital in Shebin El Kom was 30 children (15 children received family empowerment model sessions and 15 children did not received sessions. They selected based on the following criteria.

i. Inclusion criteria:

1. Age of children ranged from 8-12 years old.

2. Children were diagnosed with chronic kidney diseases and no history of kidney transplantation and end-stage 
renal diseases.

3. Free from any other chronic diseases.

4. Parents can read and write.

ii. Exclusion criteria:

1. Children with special needs who cannot be educated or need special education such as mental retardation, autism, deaf and damp because they will not be able to communicate.

2. Patients' interest to stop cooperating in the study.

\subsection{Data Collection Tools}

In order to achieve the purpose of the study, two tools were utilized for data collection:-

i. Tool one: Social characteristics sheet. It was developed by the researcher to assess information about children and their parents. It was divided into two parts:

(a) Part one: characteristics of children. It includes child's name, age, sex, school grade and residential.

(b) Part two: characteristics of parents. It includes age of parents, level of education, and their job.

ii. Tool two: Core Pediatric Quality of Life (QoL), Version 4 Questionnaire Sheet (Core Ped QoL, version 4). It was confirmed by varni, 1999 [19]. It included 23 questions, and these questions covered the following two dimensions: -

(a) Physical dimension: it was included 8 questions.

(b) Psychosocial dimension: it was included 15 questions ( 5 on emotional function, 5 on social function, and 5 on school function).

(c) Scoring for Core Ped QoL, version $4=$ items were reversed and linearly transformed to a 0-100 scale as follow 0 (Never) $=100,1$ (Almost never) $=75,2$ $($ sometimes $)=50,3($ often $)=25,4$ (Almost always $)=$ 0 , so that the higher scores indicated better health related quality of life. Total scored were sum of all the items over the number of items answered on all scale.

\subsection{Methods of Data Collection}

i. Written permission:

Prior to data collection, an oral permission to carry out the study was obtained from the director of Menoufia University Hospital and Teaching Hospital in Shebin El Kom after explaining the purpose of the study and methods of data collection.

ii. Validity

For validity assurance, four instruments were provided to a jury including one professor of pediatric nursing, two assistant professors of pediatric nursing and two assistant professors in pediatrics.

iii. Reliability:

Reliability of the tools was done to determine the extent to which items in the questionnaire were related to each other by Cronbach's co-efficiency alpha test for the questionnaire $(\mathrm{r}=0.89)$.

iv. Ethical Considerations:

A verbal consent was obtained from the care givers of children who meet the inclusion criteria to participate in the study. At the initial interview with parents and their children, they were informed about the purpose, procedure and benefits of the study and expected outcomes. An explanation was provided that participation in the study was voluntary and harmless. Also, parents were known that they can out from the study at any time.

(a) Confidentiality and anonymity of patients was assured through coding all data and putting all paper in a closed cabinet.

(b) Questionnaires were fulfilled by the researcher and child and his/her parents, through personal interview.

v. Pilot study:

It was carried out on five children and their caregivers in each group (10\% of the sample) to test the practicability, applicability and to estimate the needed time to fill the instruments. No necessary modifications were done. Therefore, the pilot study was included in the total sample.

\subsection{Data Collection Procedure}

i. Data collection started from February 2015 to August 2016. It collected during work hours one day a week in outpatient clinic of Pediatrics sub-specialists of children's renal diseases.

(a) An official permission was obtained from the Dean of the faculty of nursing to conduct the study and collect the necessary data.

(b) The researcher introduced herself to the child and his/her care giver and explained the procedure of research.

ii. The researcher started to collect data about social characteristics of parents and their children.

iii. The questionnaire was filled by the children and their parents or by researcher. They filled twice before and one month after implementation of family empowerment session in the study group I and study group II in identical time points.

iv. Researcher after agreement of the participant, assessed needs, resources, and weak points of the of the study groups in a building near one of the outpatient clinic of Pediatrics sub-specialists of children's renal diseases, and designed of empowerment program content. Then, family empowerment model was applied based on its steps and stages. These steps included six sessions. Each session take 45 minutes according to children's needs and tolerance. Three group discussion sessions were held for the parents too.

v. Control groups no received intervention.

vi. Family empowerment model contains four steps: the first step was improved and increased participants knowledge regarding chronic kidney failure. The researcher was used several teaching methods as PowerPoint presentations, models, posters, team teaching, question-and-answer sessions, and roleplaying teaching methods. These methods helped the researcher to increase levels of participants' knowledge. The participants were divided into 4-5 
individual subgroups based on the type of disease, and received educational contents in a total of six 45-min sessions (four sessions for theory and two sessions for practical presentation) as follows: First session, the children introduced themselves. Then, researcher were explained the general and behavioral goals, the evaluation method, and the duties of the subjects in educational sessions. Also, they received information about physiology and anatomy of kidney. Second session, in this session the participants received information about causes of kidney failure, clinical manifestation, complications, and prognosis. Third session, the researcher explained more information about nutrition and laboratory tests and their normal values. Fourth session, finally, the researcher discussed with the children about the medication importance. For instance, the researcher explained the effect on nutrition on the disease. Then, the participants started discussing about it, based on their experiences and the researcher conducted the session. At the end of each session, the given materials were finalized and the questions were answered, and finally, the data and goal of the next session were determined. In each session, two questions were asked to the children in relation with the subjects of former sessions to evaluate the level of their learning.

vii. The Second step was aimed to enhance and improve self-efficacy to all participants. It included two sessions were held involving demonstrations. In this step, the researcher was explained practice that required for measuring weight and blood pressure and these practices were taught to the children by demonstration and re- demonstration teaching methods.

viii. Third step was help participants to increase their selfesteem through educational participation. In this step, the researcher helped the children to participate with hem/here in training their parents to know more about chronic kidney failure. Also, to ensure the parents were understand the basic knowledge and teaching content through their children's training, the researcher involved them in three 45-minute training sessions about chronic kidney disease, diet, physical activity, treatment and complications of diseases. After two weeks the last session, the researcher called all the participants to follow up on the implementation of the skills learned and to ensure that the taught materials were being implemented. Furthermore, the participants were given the researcher's telephone number to ask any questions, if necessary.

ix. Fourth step was the evaluation process of participant, the researcher evaluated knowledge at the beginning of each session. The children were orally asked some questions from the previous session. Also, Selfefficacy was evaluated by asking the children to demonstrate two learned practical skills. Meanwhile, self-esteem was assessed by the level of the children's cooperation in the participatory training when giving back the training cards comprising their parents' notes.

x. Final evaluation which assessed one month after completion of intervention, the questionnaires was reevaluated by the same tools to both groups.

xi. For moral purpose, the handbook give to the group I was also give to the group II after the questionnaires had been filled out.

\subsection{Data Analysis}

The Statistical Package for Social Studies (SPSS) version 20.0 was used. Data were coded and summarized using means and standard deviation for quantitative variables and percentage distribution for qualitative variables. Comparison of means was performed using paired t-test, independent t-test.

\section{Results}

Table 1. Distribution of children regarding their social characteristics.

\begin{tabular}{|c|c|c|c|c|c|}
\hline \multirow{2}{*}{ Items } & \multicolumn{2}{|l|}{ Group I } & \multicolumn{2}{|l|}{ Group II } & \multirow{2}{*}{ Test of significance $\&$ p-value } \\
\hline & No $=30$ & $\%$ & No $=30$ & $\%$ & \\
\hline Children Age $($ Mean \pm SD) & \multicolumn{2}{|l|}{$(11.53 \pm 2.45)$} & \multicolumn{2}{|l|}{$(11.79 \pm 2.58)$} & $0.76^{\mathrm{ns}}$ \\
\hline \multicolumn{6}{|l|}{ Gender } \\
\hline Male & 16 & 53.3 & 20 & 66.6 & \multirow[t]{3}{*}{$0.44^{\mathrm{ns}}$} \\
\hline Female & 14 & 46.6 & 10 & 33.3 & \\
\hline \multicolumn{5}{|l|}{ Residential } & \\
\hline City & 10 & 33.3 & 8 & 26.6 & \multirow[t]{2}{*}{$0.39^{\mathrm{ns}}$} \\
\hline \multicolumn{5}{|l|}{ Educational level } & \\
\hline Elementary school & 21 & 70.0 & 18 & 60.0 & \multirow[t]{2}{*}{$0.96^{\mathrm{ns}}$} \\
\hline Primary school & 9 & 30.0 & 12 & 40.0 & \\
\hline
\end{tabular}

$\mathrm{NB}:{ }^{\mathrm{ns}}$ means $\mathrm{p}>0.05$ not significant

Table 1 showed demographic characteristics of studied children. It was obvious from this table that the mean and standard deviation of studied children age was $(11.53 \pm 2.45$ and $11.79 \pm 2.58$ ) in the two study groups respectively. Regarding children gender, approximately more than one half of studied children were males (boys) $(53.3 \%, 66.6 \%)$ in the 
two study groups. According to the children and family residential the majority $(66.6 \%, 73.3 \%)$ of studied children in both groups live in village. Also, the same table revealed no statistical significance differences between the studied groups regarding all items.

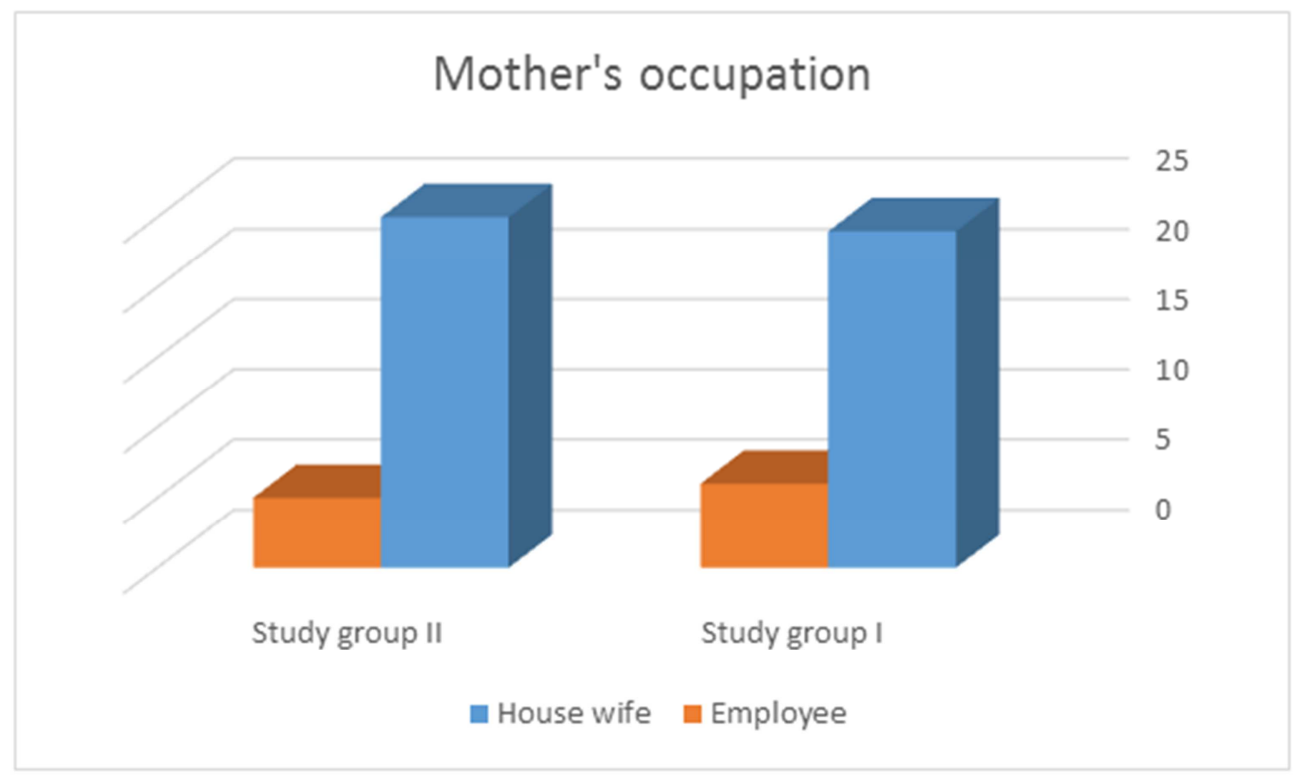

Figure 1. Distribution of the mother regarding their occupation.

Figure 1 revealed that the majority $(80.0 \%, 83.3 \%)$ of mothers were house wife in the study group 1 and study group II respectively.

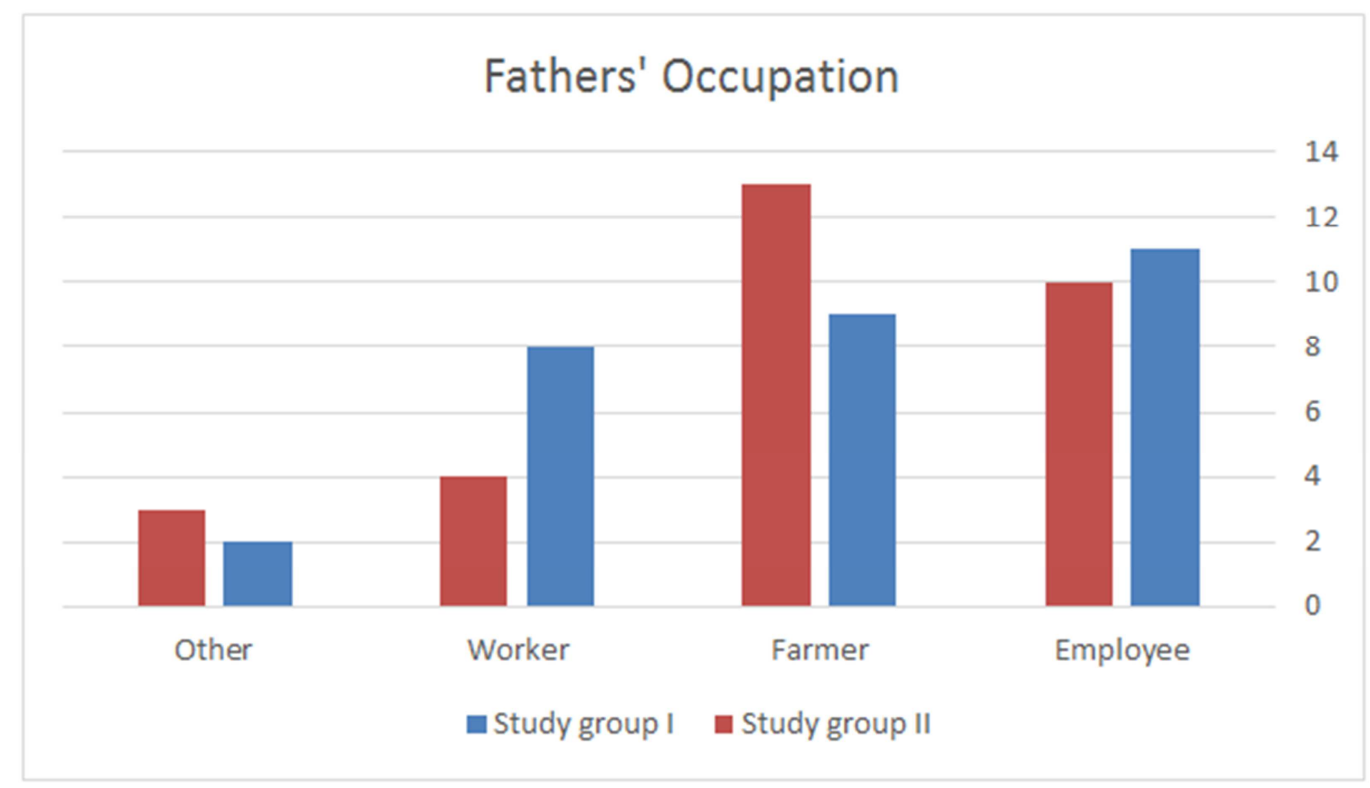

Figure 2. Distribution of the fathers regarding their occupation.

Figure 2 showed that the largest percentage (36.6\%) of fathers were employee in the study group I respectively, while the largest percentage (43.3\%) of fathers were farmer in the study group II respectively. 


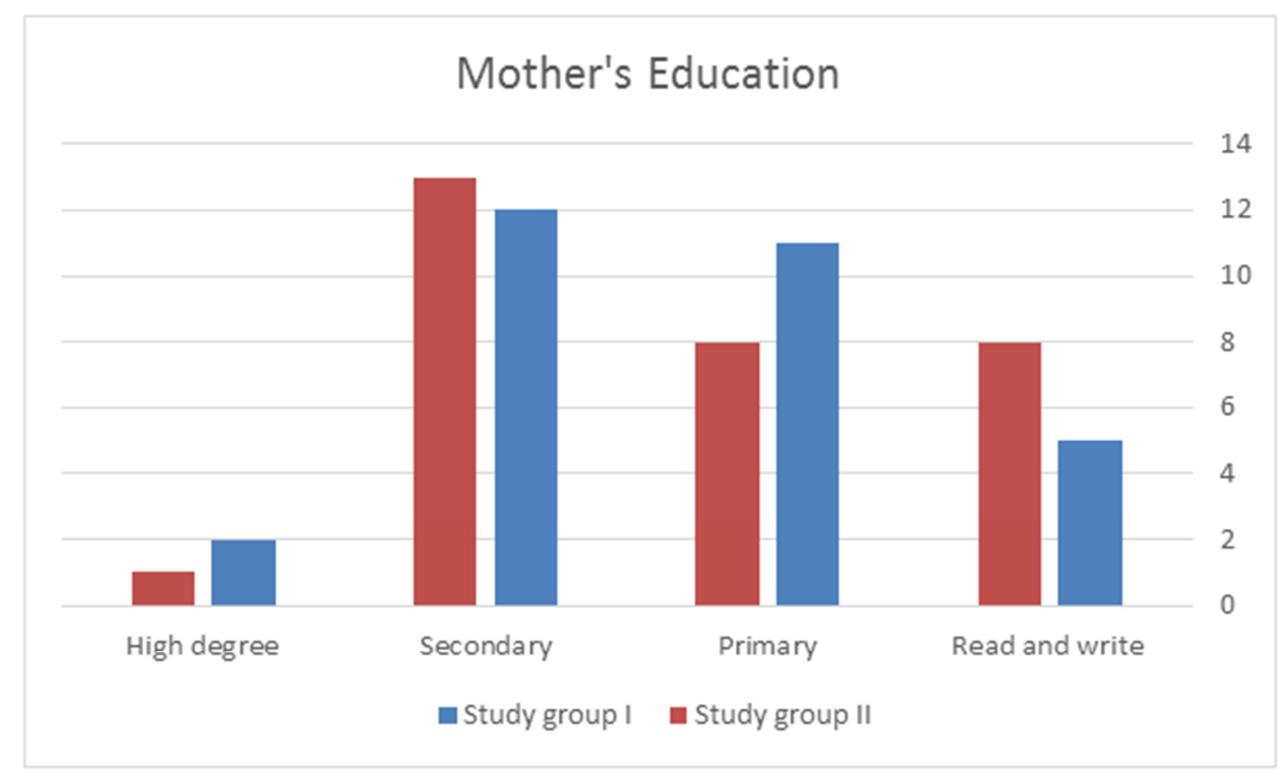

Figure 3. Distribution of mothers regarding their education.

Figure 3 showed that approximately less than half $(40.0 \%, 43.3 \%)$ of mothers in the study group I and study group II had a secondary educational respectively.

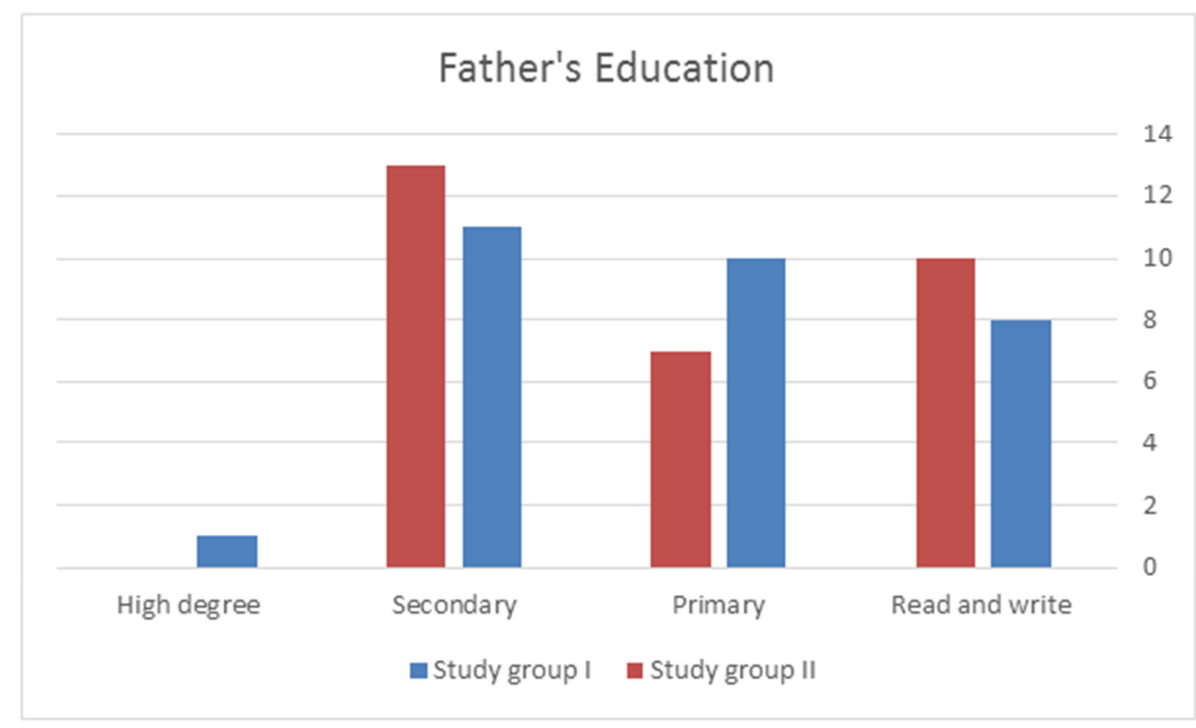

Figure 4. Distribution of fathers regarding their education.

Figure 4 showed that approximately less than half $(36.6 \%, 43.3 \%)$ of fathers in the study group I and study group II had a secondary educational respectively.

Table 2. Means and SD of children quality of life on pre-intervention (before family empowerment sessions) in the two studied groups.

\begin{tabular}{lllll}
\hline QOL dimension & Study group I no= (30) & Study group II no=( 30) & t- test & P-value \\
\hline Physical (Mean \pm SD) & $79.5 \pm 12.8$ & $78.1 \pm 16.3$ & 0.37 & $0.71^{\text {ns }}$ \\
Psychosocial_(Mean \pm SD & $78.1 \pm 13$ & $77.0 \pm 14.1$ & 0.31 & $0.68^{\text {ns }}$ \\
Total & $79.5 \pm 13$ & $78.1 \pm 12.8$ & 0.42 & $0.72^{\text {ns }}$ \\
\hline
\end{tabular}

NB: QOL: Quality of life ${ }^{\text {ns }}$ means $p>0.05$ not significant

Table 2 showed mean of children quality of life on preintervention (before family empowerment sessions) in the two studied groups. As indicated in the table, there was no statistically significant difference in the mean scores of QOL in the both study groups regarding physical $(P=0.71)$, psychosocial $(P=0.68)$ dimensions and the total score of QOL $(P=0.72)$ before intervention. 
Table 3. Means and SD of children Quality of life on post-intervention (one month after family empowerment sessions) in the two studied groups.

\begin{tabular}{lllll}
\hline QOL dimension & Study group I no=(30) & Study group II no=(30) & t- test & P-value \\
\hline Physical (Mean \pm SD) & $85.8 \pm 8.3$ & $78.4 \pm 14.1$ & 2.49 & $<0.01^{*}$ \\
Psychosocial_(Mean \pm SD & $86.0 \pm 6.5$ & $77.8 \pm 15.0$ & 2.75 & $<0.005^{* *}$ \\
Total & $86.8 \pm 7.1$ & $78.1 \pm 13.8$ & 1.71 & $<0.05^{*}$ \\
\hline
\end{tabular}

QOL: Quality of life $\mathrm{P}$ value $<0.05 *=$ significantly **= high significantly

Table 3 showed mean and SD of children quality of life on post intervention (one month after family empowerment sessions) in the two studied groups. The table clarified that there was a statistically significant difference between study group I and study group II after conducting the family empowerment sessions regarding physical, psychosocial dimensions and the total score of QOL $(0.01,0.005,0.05)$ respectively.

Table 4. Mean and SD of children quality of life in study group 1 on pre-intervention (before family empowerment sessions) and post-intervention (one month after family empowerment sessions).

\begin{tabular}{llll}
\hline QOL dimension & $\begin{array}{l}\text { pre-intervention (before family empowerment } \\
\text { sessions) }\end{array}$ & $\begin{array}{l}\text { post-intervention (one month after family } \\
\text { empowerment sessions) }\end{array}$ & $\begin{array}{l}\text { t- test } \\
\text { P }- \text { value }\end{array}$ \\
\hline Physical & $79.5 \pm 12.8$ & $85.8 \pm 8.3$ & 2.26 \\
Psychosocial & $78.1 \pm 13$ & $86.0 \pm 6.5$ & $<0.05 *$ \\
Total & $79.5 \pm 13$ & $86.8 \pm 7.1$ & $<0.005^{* *}$ \\
\hline
\end{tabular}

NB: QOL: Quality of life P value $<0.05 *=$ significantly $* *=$ high significantly

Table 4 showed mean and SD of children quality of life in study group I on pre-intervention (before family empowerment sessions) and post-intervention (one month after family empowerment sessions). The table illustrated that children had better mean scores of quality of life regarding physical dimension, psychosocial dimension and total mean scores of QOL on post-intervention (one month after family empowerment sessions) in study group1

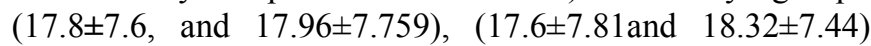
respectively. So, there were statistical significant differences between two groups regard mean scores of children quality of life at $1 \%$ and $5 \%$ level of statistical significance.

\section{Discussion}

A chronic kidney disease is considering one of the major health problems in children who are age under 18 years. It is a very complicated disease that causes life threatening. Children with chronic kidney diseases like chronic kidney failure need continuous supportive care that helps them to cope with this disease. Empowerment of the families is the effective way that helps children to have improved QOL. Family empowerment is interaction of health professionals with the families, that it causes a sense of control of families' life and leads to getting to positive changes in the direction of power, ability, and enhancement of skills in families [20].

The current study hypothesized those children with chronic kidney diseases who received family empowerment model sessions will have better quality of life than children who did not. In relation to hypothesis, the present study illustrated that there was no significant difference in the mean total scores of QOL before intervention in the two groups, this can be interpreted that patients and theirs family don't have enough knowledge and skill about family empowerment model that can help children to have enough confidence and better quality of life.
This result was consistent with Allahyari et al., (2006) who found that family empowerment model in children with CKD would enhance their self-confidence as well as improve their self-management skills [21].

The current study showed that there was statistical significant difference between two groups regarding the total mean scores of QOL after intervention. It is inferred that the family empowerment model helped children with chronic kidney disease and their family to improve their quality of life by improve physical and psychosocial, decrease hospitalization rates and costs and decrease school absenteeism.

This result was consistent with Zohreh et al., (2014) who found that results of their study administration of family empowerment model can increase the QOL of children of age 8-12 years with chronic renal diseases [22]. Also their results as well as many others clearly confirmed the effectiveness of educational intervention in children with chronic kidney disease management. Moreover, welldesigned educational programs, which were correctly applied for children and parents together, should be considered a part of good clinical care in in children with chronic kidney disease.

The result of the present study revealed that, children with CKD had lower quality of life regarding physical dimensions pre intervention. This could be rationalized as such a finding might be due to difficulties followed by the CKD. These patients usually suffer from many physical symptoms and side effects. This result was consistent with Elsayed et al., (2012) who found that the daily activity of most of children with CKD declined and rate of physical complaints in these children was more than healthy Children [23].

Moreover, these results came in agreement with Rambod et al., (2011) who documented that children with CKD could not obtain an appropriate score in physical dimension of quality of life [24]. So, the necessity of knowing physical 
needs in these children is determined more than ever. Also, training program and attention to these patients should be done even up to in small village.

The result of the present study clarified that, there was improvement in physical domains after implementing the family empowerment model session was obvious. This result was supported by Marzieh et al., (2016) who indicated that quality of life of these patients had a significant difference in physical domain after the training [25].

In the same context the present study revealed that children with CKD had poor quality of life in psychosocial dimension before implementing the family empowerment model session. This finding was related to many causes such as children body image compared to their peers, recurrently referred to the hospital, side effect of disease, and fatigue from elongated treatments that affect patients mentally and emotionally and socially. In this regard Park, (2012) showed that the major effective problems of treatment follow-up related to mental and emotional problems such as fatigue [26]. It caused by the prolongation of treatment, hopelessness toward future, lack of confidence to do treatment affairs and lack of will to continue the treatment. In addition, it was shown that psychological problems were of higher importance than social and economic problems in treatment follow-up.

In this respect Pakpour et al., (2006) documented that almost half of the patients with chronic diseases had problems in self-care due to psychological problems and this caused reduction in their quality of life [27]. Moreover, the current study results revealed that there was improvement in psychosocial domains after implementing the family empowerment model session was obvious. These result were consistent with the study of Nygårdh, (2013), it was indicated that quality of life of these patients had a significant difference in psychosocial domain after the training [28].

\section{Conclusion}

Based on the findings of the present study, the following is concluded: implementation of family empowerment model improved and increased the quality of life for children with chronic kidney diseases.

\section{Recommendations}

In the light of the findings obtained from the current study and its conclusion, the following recommendations are suggested:

i. Family empowerment model should be used in inpatient and outpatient children's health care.

ii. Conduct further study in other age groups and for other chronic diseases.

\section{References}

[1] National Kidney Foundation, (2010). Clinical practice guidelines for chronic kidney disease evaluation, classification, and stratification. American Journal of Kidney Diseases, 39(1-2):S1-266.
[2] US Renal Data System (USRDS). 2010 Annual Data Report: Atlas of Chronic Kidney Disease and End-Stage Renal Disease in the United States. Bethesda, Md: National Institutes of Health, National Institute of Diabetes and Digestive and Kidney Diseases; 2010. Retrieved from https://www.usrds.org/adr.htm.

[3] Gad, (2009). Nurses Application of infection control prevention in hemodialysis unit at El Mansura University children hospital. Egypt. Journal of the Egyptian Public Health Association, 86(1-2), 5-12.

[4] Behrman RE, Kligman RM, Stanton BF, Schor MF, Geme JW, (2011). Nelson text book of pediatrics, 19th ed. Philadelphia: Elsevier: Saunders.

[5] Mark RH, (2007). Chronic kidney disease in children: state of the art. Pediatric Nephrology, 22(10), 1687-8.

[6] Lai W, (2009). Quality of life of children with end stage renal disease: Does treatment modalities matter? Perit Dai Lint; 190-191.

[7] Tong A, Lowe A, Sainsbury P and Craig J, (2008). Experience of parents who have children with chronic kidney disease. A systematic review of qualitative studies. Pediatrics Nephrology, 21(11), 349-360.

[8] Kenna A, Keating L, Vigneux A, Stevens A and Geary D, (2006). Quality of life in children with chronic kidney disease: Patient and care givers assessments. Journals Medical Nephrology Dialysis Transplantation; 21(7), 1899-1905.

[9] Abd El-Tawab R, (2010). Factors affecting quality of life for adolescent undergoing hemodialysis. Thesis of master degree in Pediatric Nursing. Faculty of Nursing. Benha University.

[10] Scarpelli C, Paival S, Varni L, Viegas C, and Allison P, (2007). The Pediatric Quality of Life Inventory, family impact module: reliability and validity of the Brazilian version; 1-3.

[11] Damiano P, Tyler M, Romitti P, Momany E, Jones P, Michael P, (2009). Health related quality of life among pre-adolescent children with oral clefts: the mother perspective. Pediatrics; 120(2), 10-15. 20.

[12] Teimori F, Alhani F, Kazemnazhad A,( 2010). The effect of family-centered empowerment model on the quality of life of school- age Asthma children. Nursing Resesrch, 6(52), 63.

[13] Banach M, Iudice J, Conway L, Couse LJ, (2010). Family Support and Empowerment: Post Autism Diagnosis Support Group for Parents. Iran Journal of pediatrics, 33(2), 69-83.

[14] Graves KN, Shelton TL, (2007). Family empowerment as a mediator between families centered systems of care and changes in child functioning: Identifying an important mechanism of change. Journal of Child and Family Studies, 16(5) 56-66.

[15] Marciano RC, Soares CM, Diniz JS, Lima EM, Silva JM, Canhestro MR, et al., (2011). Behavioral disorders and low quality of life in children and adolescents with chronic kidney disease. Pediatric Nephrology, 6(281), 90.

[16] National Kidney and Urologic Diseases Information Clearinghouse (NKUDIC), (2014). Overview of the Kidney Disease in Children. American Journal of Kidney Diseases, 4(4), 5167. 
[17] Gregory, Derek, Johnston R, Pratt, Geraldine W, Michael et al., (2009). Quality of Life. Dictionary of Human Geography, 5th ed., Oxford: Wiley-Blackwell. ISBN 978-1-4051-3287-9.

[18] Pudji M, (2011). The model of family empowerment program for community development in West. Java, Journal of Agricultural Extension and Rural Development. 3(11), 193201.

[19] Varni J, Seid M and Rode G, (1999). The ped's QO1 TM; Measurement model for the pediatric quality of life inventory. Medical Care, 37, 126-139.

[20] Kopple JD, (2010). Clinical practice guidelines for nutrition in chronic renal failure. American Journal of Kidney Diseases. 37(1-2):S66-70.

[21] Allahyari I, Alhani F, Kazemnezhad A, Izadyar M, (2006). The effect of family empowerment model-based on the quality of life of school-age children with thalassemia. Iran Journal of Pediatrics, 4, 455-61.

[22] Zohreh Ghazavi, Marzieh Sadat Minooei, Zahra Abdeyazdan and Alaleh cheissan, (2014). Effect of family empowerment model on quality of life in children with chronic kidney diseases. Iran Journal Nursing Midwifery Research. 19(4), 371-375.

[23] Elsayed E, El-SoreetyW, Elawany Th, and Nasar F, (2012).
Effect of nursing intervention on the Quality of life of children undergoing hemodialysis. Life Science Journal, 9(1), 19-25.

[24] Rambod M, Rafii F, Shirazi MK, Ghodsbin F, Heydari ST, (2011). Comparison of the quality of life in elderly with young and middle age chronic renal failure patients. Salmand, 6(52), 8.

[25] Marzieh Saadat, Minooei, Zahreh Ghazavi, Zahra Abdeyazdan and Alaleh cheissan, (2016). The Effect of the Family Empowerment Model on Quality of Life in Children with Chronic Renal Failure: Children's and Parents' Views, Iran Journal Nursing Midwifery Research, 8(4), 36854.

[26] Park KS, Hwang YJ, Cho MH, Ko CW, Ha IS, Kang HG, et al., (2012). Quality of life in children with end-stage renal disease based on a PedsQL ESRD module. Pediatrics Nephrology, 27, 2293-2300.

[27] Pakpour A, Panahi D, Yekaninejad M, Ebadi F, Izy H, (2006). A comparative study on health related quality of life in hemodialysis patients and healthy people. Health management., 9(55), 62.

[28] Nygårdh, (2013). A quality improvement project on empowerment in chronic kidney care- an interactive research approach, Nephrology nursing journal: journal of the American Nephrology Nurses' Association 39, 285. 